\title{
Hazards due to large wood accumulations: Local scour and backwater rise
}

\author{
Isabella Schalko ${ }^{1, *}$, Lukas Schmocker ${ }^{1}$, Volker Weitbrecht ${ }^{1}$, and Robert M. Boes ${ }^{1}$ \\ ${ }^{1}$ Laboratory of Hydraulics, Hydrology and Glaciology (VAW), Swiss Federal Institute of Technology \\ Zurich (ETH Zurich), Zurich, Switzerland
}

\begin{abstract}
Large wood (LW) in rivers increases the flow variability and provides habitats for various species. During flood events, transported logs can accumulate at river infrastructures and increase the flood hazard. LW accumulations result in an upstream backwater rise and may increase local scour, for instance at bridge piers. Consequently, estimates of the resulting backwater rise and local scour are necessary to improve the flood hazard assessment. This study presents the findings of flume experiments with a movable bed on local scour and backwater rise due to LW accumulations. The approach flow conditions and the bed material were varied systematically for a specific LW accumulation volume. For all experiments, the initial condition for the bed material was defined as weak transport, since the bed shear stress was slightly below the critical bed shear stress for incipient motion. The inflow Froude number was identified as the governing parameter for backwater rise due to LW accumulations. The present study confirms the hypothesis that the resulting local scour reduces backwater rise. For the local scour, the unit discharge and the grain size diameter are the decisive parameters.
\end{abstract}

\section{Introduction}

Large wood (LW) is defined as logs with a diameter $\geq 0.1 \mathrm{~m}$ and a length $\geq 1.0 \mathrm{~m}[1,2]$. In a river, LW accumulations can occur in shallow water areas as well as at natural or artificial obstructions. These accumulations play an essential role for the river ecosystem, as they increase the variability of flow and morphological structures. They can provide habitats for e.g. fish species and enable the deposition and storage of nutrients or sediments [3]. The transport of LW can be described as uncongested (i.e. single log transport), congested (i.e. logs are transported in bulk) [4], or hypercongested (i.e. not saturated logs are transported in bulk at the front) [5]. Congested or hypercongested LW transport can result in enormous accumulations at river infrastructures during a flood event. These LW accumulations can lead to (1) backwater rise and consequently flooding of the surrounding area, (2) local scour at river infrastructures, as well as (3) an interruption of the sediment continuity. Therefore, engineering measures as e.g. racks or nets $[6,7]$ are necessary to mitigate LW accumulation risk (Figure 1). A proper design of these measures is key to a successful flood hazard management.

\footnotetext{
*e-mail: schalko@vaw.baug.ethz.ch
} 

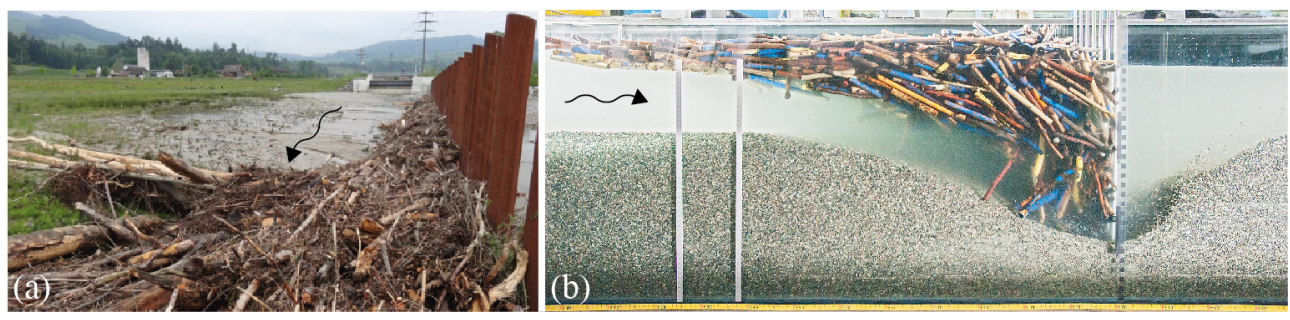

Figure 1. (a) LW accumulation at the retention rack at the River Kleine Emme, Switzerland (Photo: VAW), and (b) model test of LW accumulation at a retention rack (Photo: VAW)

The investigations on backwater rise due to LW accumulations have substantially increased within the last decades. Physical experiments to quantify backwater rise due to LW accumulations, focusing on Alpine regions, were conducted by Knauss [8], Rimböck [9], Schmocker and Hager [10], and Hartlieb [11]. In addition, backwater rise was investigated in specific case studies [12]. Schalko et al. [13] included the effect of organic fine material, e.g. branches or leaves, in a LW accumulation on backwater rise.

Only few studies investigated the influence of LW accumulation on scour, thereby focusing mainly on bridge pier scour. Laursen and Toch [14] studied local scour around bridge piers and abutments due to a LW accumulation. The results qualitatively showed that the LW accumulation changed the approach flow conditions and led to deeper and larger scour holes. Melville and Dongol [15] modeled the LW accumulation body at a bridge pier as rafts with smooth, impermeable, regular shapes. The parameters affecting the local scour, besides the LW accumulation characteristics, were approach flow depth and velocity, sediment size and grading, as well as pier size, shape, and orientation to the flow. Lagasse et al. [16] conducted flume experiments, including different accumulation porosities (impermeable versus $25 \%$ porosity). Compared to the size, shape, and location of the LW accumulation body, the roughness and porosity had only a minor effect on the resulting local scour. Pagliara and Carnacina [17] experimentally studied the influence of the transverse cross-sectional geometry of LW accumulations on local scour at bridge piers. The blockage area was identified as the decisive parameter affecting the resulting scour. The geomorphic and hydraulic impact of LW elements in sand-bed channels were examined by Wallerstein et al. [18] using flume experiments. The flow conditions were chosen below the threshold for incipient motion to investigate geomorphic effects solely due to the LW elements. As a result, the LW element size was the governing parameter for scour depth and size. Wallerstein [19] developed a model to describe constriction scour due to LW accumulations. The analytical model was validated with field and experimental data of the Mississippi River [18] and allows to estimate scour rate and depth due to a partial LW blockage.

As the majority of the studies on backwater rise due to LW accumulations was conducted with a fixed bed, the knowledge on the interaction between backwater rise and scour is still limited. A movable river bed may decrease backwater rise, while the resulting scour may lead to damages at the river infrastructure itself. Studies investigating scour due to LW accumulations focused on local scour at bridge piers or constriction scour (partial blockage). The main objectives of this study are to analyze and quantify the resulting backwater rise and local scour due to (spanwise) LW accumulations for different approach flow conditions and bed material. This study is part of the interdisciplinary research project WoodFlow [20]. 


\section{Methods}

The effect of the approach flow conditions and LW accumulation volume on backwater rise $\Delta h$ and scour depth $S$ was tested for uniform and non-uniform bed material with different mean grain size diameters $d_{m}$ using small scale model tests. Based on typical log dimensions in rivers (e.g. [21]) the scaling factor was set to $\lambda=30$. In addition, the accumulation process of the small-scale model tests was validated with close-to-prototype tests [22]. The physical experiments were conducted in an $8.0 \mathrm{~m}$ long, $0.4 \mathrm{~m}$ wide, and $0.7 \mathrm{~m}$ deep channel at the Laboratory of Hydraulics, Hydrology and Glaciology (VAW) of ETH Zurich. The test setup and notation are illustrated in Figure 2. The intake was $0.66 \mathrm{~m}$ long and equipped with two flow straighteners. The downstream flow conditions were regulated with a needle weir. The inflow discharge $Q$ was measured with an electromagnetic flow meter (IDM) and regulated with a valve to a maximum of $70 \mathrm{l} / \mathrm{s}$. The bottom slope can be varied manually between $S_{o}=0 \ldots 10 \%$. The approach flow conditions (subscript $o$ ) representing uniform flow without LW accumulation are defined by approach flow depth $h_{o}$, Froude number $\mathrm{F}_{o}$, or velocity $v_{o}=Q /\left(B h_{o}\right)$ with $B=$ channel width. A rack with seven round bars of $0.008 \mathrm{~m}$ diameter and an axial spacing of $0.05 \mathrm{~m}$ was vertically placed $3.4 \mathrm{~m}$ downstream of the intake. The rack itself had a negligible effect on the approach flow conditions and did not induce backwater rise. The flow depths ( $\Delta h$ and $h=$ flow depth with accumulation) were measured with Ultrasonic Distance Sensors (UDS) and a point gauge to obtain backwater rise $\Delta h=h-h_{o}$. A given solid LW volume $V_{S}=23 \mathrm{dm}^{3}$ was continuously added to the flume in $5 . .10 \%$ packages to model a natural formation of a LW accumulation. During pre-tests, $V_{S}$ was defined such that $\Delta h$ reaches a maximum after the addition of $100 \%$ of $V_{S}$. The LW accumulation consisted of $\operatorname{logs}$ (subscript $L$ ) with a mean diameter $d_{L m}$ and length $L_{L}$.

A $0.5 \mathrm{~m}$ long ramp of boulders with a diameter of $\approx 0.10 \mathrm{~m}$ was installed at the upstream end of the flume to provide a smooth flow transition. The movable bed was inserted to the flume with a height $h_{B}=0.35 \mathrm{~m}$ and length $L_{B}=5.5 \mathrm{~m}$. The bed level was fixed at the downstream end of the flume using a $2 \mathrm{~m}$ long plate with a roughness coat. The scour depth $S$ was scanned after each run in a $0.025 \mathrm{~m}^{2}$ raster with a laser distance sensor placed on a positioning system, which was manually moved in the $x$ - (flow direction) and $y$-direction (spanwise direction). The origin of the $x, y$-coordinate system was at the rack at $h_{B}$. In addition, the scour depth at the rack (subscript $R$ ) $S_{R}$ was measured with a point gauge.

\subsection{Model large wood and bed material}

A model LW mixture was tested with a mean log diameter $d_{L m}=10 \mathrm{~mm}$ and log lengths $L_{L}=5 \ldots 10 \mathrm{~mm}$ (Figure 3). The density of the model LW $\rho_{L W} \approx 700 \mathrm{~kg} / \mathrm{m}^{3}$ is comparable to prototype values [23]. In the beginning, uniform bed material was tested in order to avoid additional effects due to the formation of an armor layer (Figure 4a). For comparison, additional experiments were conducted with non-uniform bed material $(\sigma \approx 2.6$; Figure $4 \mathrm{~b})$. The mean grain size diameters varied from $d_{m}=2.7 \mathrm{~mm}, 5.2 \mathrm{~mm}, 5.4 \mathrm{~mm}$, to $13.1 \mathrm{~mm}$.

\subsection{Test program and procedure}

The test program is listed in Table 1 . In each test (e.g. A1), $V_{S}$ was continuously increased from $5 \%$ to $100 \%$ of $V_{S}=23 \mathrm{dm}^{3}$. The reproducibility was evaluated by conducting the same test three times (e.g. Tests A1-A3). The effect of the bed material on the resulting scour and backwater rise was analyzed by varying the mean grain size diameter $d_{m}$ (Tests A1-A12) of uniform bed material for different approach flow conditions. Non-uniform bed material was investigated for one setting of approach flow conditions (Tests A13-A15). In order to solely 


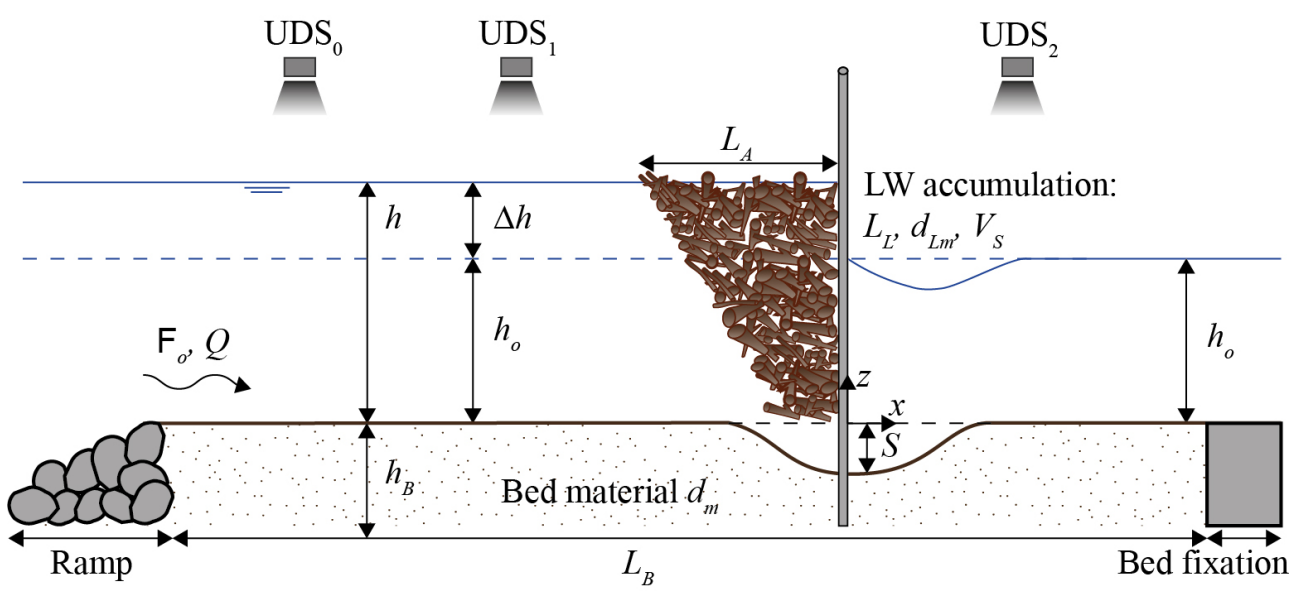

Figure 2. Test setup and notation. Approach flow conditions $\left(\mathrm{F}_{o}, h_{o}\right)$ and discharge $Q$ were measured without LW accumulation. Flow depths $h_{o}$ and $h$ were measured using Ultrasonic Distance Sensors $\left(\mathrm{UDS}_{0-2}\right)$ and the resulting backwater rise was computed as $\Delta h=h-h_{o}$. LW accumulation characteristics comprise $\log$ length $L_{L}$, mean $\log$ diameter $d_{L m}$, solid LW volume $V_{S}$, and accumulation length $L_{A}$. Bed material characteristics are bed material height $h_{B}$ and length $L_{B}$, mean grain size diameter $d_{m}$, and scour depth $S$.

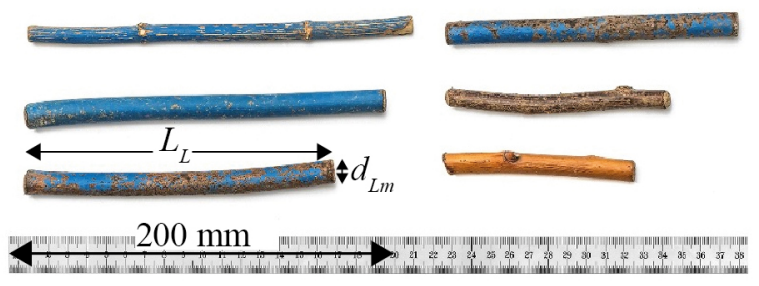

Figure 3. Model large wood

(a)

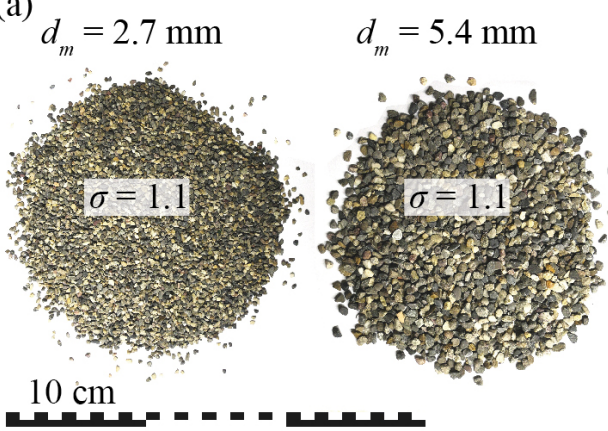

$d_{m}=13.1 \mathrm{~mm}$

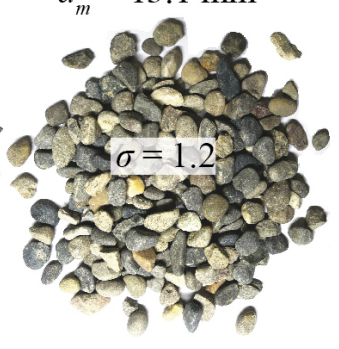

(b) $d_{m}=5.2 \mathrm{~mm}$

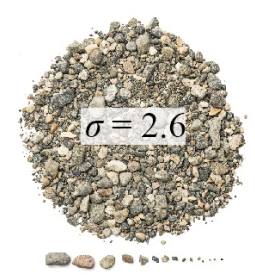

Figure 4. Mean grain size diameter $d_{m}$ of (a) uniform versus (b) non-uniform bed material 
Table 1. Test program for constant $d_{L m}=10 \mathrm{~mm}$ and max. $V_{S}=23 \mathrm{dm}^{3}$

\begin{tabular}{|c|c|c|c|c|c|c|}
\hline $\begin{array}{c}\text { Test } \\
\text { series }\end{array}$ & $\begin{array}{c}Q Q \\
{[1 / \mathrm{s}]}\end{array}$ & $\begin{array}{c}S_{o} \\
{[\%]}\end{array}$ & $\begin{array}{c}h_{o} \\
{[\mathrm{~mm}]}\end{array}$ & $\begin{array}{l}\mathrm{F}_{o} \\
{[-]} \\
\end{array}$ & $\begin{array}{c}d_{m} \\
{[\mathrm{~mm}]}\end{array}$ & $\begin{array}{l}\theta_{I C} \\
{[-]}\end{array}$ \\
\hline A1-A3 & 20 & 0.70 & 78 & 0.74 & 5.4 & 4 \\
\hline A4-A5 & 30 & 0.53 & 107 & 0.68 & 5.4 & \\
\hline A6-A7 & 40 & 0.45 & 132 & 0.65 & 5.4 & \\
\hline A8 & 20 & 0.29 & 92 & 0.57 & 2.7 & 0.04 \\
\hline A9 & 30 & 0.23 & 129 & 0.51 & 2.7 & \\
\hline A10 & 40 & 0.20 & 166 & 0.47 & 2.7 & $\nabla$ \\
\hline Al1 & 20 & 3.00 & 48 & 1.53 & 13.1 & 0.05 \\
\hline A 12 & 30 & 2.30 & 72 & 1.24 & 13.1 & 0.05 \\
\hline A13-A15 & 20 & 0.62 & 78 & 0.73 & 5.2 & 0.04 \\
\hline
\end{tabular}

investigate local scour due to LW accumulations, the initial condition (subscript $I C$ ) for the bed material was defined as weak transport [18] and the bed shear stress $\theta_{I C}$ was slightly below the critical bed shear stress $\theta_{c}$ for incipient motion $\left(\theta_{c}=0.047\right.$ from [24]). For a given $d_{m}$ and $Q$, the slope $S_{o}$ was adapted until the respective $\theta_{I C}$ was set. For $d_{m}=13.1 \mathrm{~mm}$, the visual bed load transport was lower compared to the smaller grain sizes. Therefore, the value for the initial condition was adapted to $\theta_{I C}=0.05$ for $d_{m}=13.1 \mathrm{~mm}$. For the non-uniform bed material, the value of the bed shear stress was visually examined and set to $\theta_{c}=0.04$. The different $d_{m}$ with $\theta_{c}=0.04 \ldots 0.05$ were chosen to cover sub- and super critical flow regimes, resulting in a range of $\mathrm{F}_{o} \approx 0.5 \ldots 1.5$. First, the approach flow depth $h_{o}$ was measured for a certain discharge $Q$ and initial bed shear stress $\theta_{I C}=0.04 \ldots 0.05$. Second, the LW was continuously added in $5 . .10 \%$ packages with the respective $d_{L m}, h$ was measured upstream of the LW accumulation at $\mathrm{UDS}_{0-1}$, and the scour depth was measured at the rack $S_{R}$. After adding $100 \%$ of $V_{S}$, the scour depth $S$ was scanned in a raster.

\section{Results}

Tests A1-A3 for uniform bed material and tests A13-A15 for non-uniform bed material confirmed the test reproducibility. For uniform bed material, the mean standard deviation (data points $n \approx 60$ ) of $\Delta h / h_{o}$ was $\leq 5 \%$. For non-uniform bed material, the mean standard deviation $(n \approx 60)$ of $\Delta h / h_{o}$ was $\leq 10 \%$ and $\leq 5 \%$ for the scour depth $S$.

The relative backwater rise $\Delta h / h_{o}$ is shown in Figure $5 \mathrm{a}$ as a function of the percentage of the added LW volume $V_{S}$ for various approach flow Froude numbers $\mathrm{F}_{o}$ and uniform bed material. The values for $\mathrm{F}_{o}=0.47$ correspond to $d_{m}=2.7 \mathrm{~mm}, \mathrm{~F}_{o}=0.68$ to $d_{m}=5.4 \mathrm{~mm}$, and $\mathrm{F}_{o}=1.24$ resp. 1.53 correspond to $d_{m}=13.1 \mathrm{~mm}$. Similar to the results of Schalko et al. [13], $\Delta h / h_{o}$ increases with increasing $F_{o}$. It can be observed that the first $20 \ldots 30 \%$ of $V_{S}$ generate the main increase of $\Delta h$, which is comparable to the findings by Schmocker and Hager [10]. In addition, the formation of a LW carpet can be observed after the addition of a certain amount of $V_{S}$. For low $\mathrm{F}_{o}$ and large $d_{m}$, a LW carpet may already form after $\approx 20 \ldots 30 \%$ of $V_{S}$. In Figure $5 \mathrm{~b}, \Delta h / h_{o}$ is plotted as a function of percentage of $V_{S}$ for uniform versus non-uniform bed material with $\mathrm{F}_{o} \approx 0.74$ and $d_{m} \approx 5.3 \mathrm{~mm}$. The development as well as the final value of $\Delta h / h_{o}$ are similar for both types of bed material and the deviations lie within the range of reproducibility. Compared to previous studies on $\Delta h$ with a fixed bed and continuous addition of LW, $\Delta h / h_{o}$ is $\approx 50 \%$ smaller for a movable bed [25]. A movable bed 

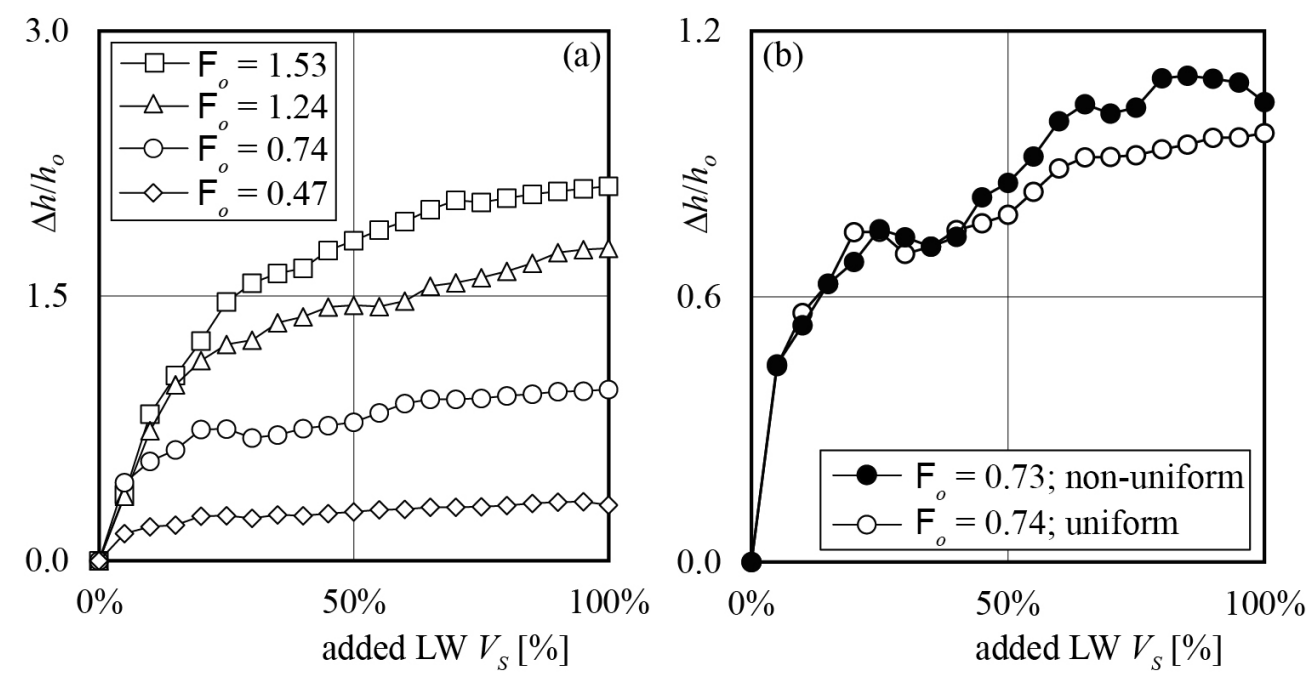

Figure 5. $\Delta h / h_{o}$ for increasing $\%$ of $V_{S}\left(\max . V_{S}=23 \mathrm{dm}^{3}\right)$ and different $F_{o}$, (a) uniform bed material (Tests A10, A4, A11-12); (b) comparison between uniform and non-uniform bed material with $\mathrm{F}_{o} \approx 0.74$ and $d_{m} \approx 5.3 \mathrm{~mm}$ (Test A1 vs. A13)

enables the scour formation, thereby increasing the open flow cross-section of the retention structure and its discharge capacity.

A longitudinal section of the average cross-sectional scour depth $S$ is shown in Figure 6a. For a given $d_{m}=5.4 \mathrm{~mm}, S$ increases with increasing discharge $Q$, and unit discharge $q=Q / B$, respectively. $S=0.13 \mathrm{~m}$ for $Q=20 \mathrm{l} / \mathrm{s}$, compared to $S=0.27 \mathrm{~m}$ for $Q=40 \mathrm{l} / \mathrm{s}$. This trend was also observed for all other investigated $d_{m}$. In Figure $6 \mathrm{~b}, S_{R}$ is plotted as a function of percentage of $V_{S}$ for uniform versus non-uniform bed material with $\mathrm{F}_{o} \approx 0.74$ and $d_{m} \approx 5.3 \mathrm{~mm}$. Similar to the results of $\Delta h / h_{o}$, the development and final value of $S_{R}$ are comparable for both uniform and non-uniform bed material. The deviations lie within the reproducibility range. Figure 7 shows the formation of $S_{R}$ for uniform bed material with $d_{m}=2.7 \mathrm{~mm}$ versus $d_{m}=13.1 \mathrm{~mm}$ and increasing percentage of $\mathrm{LW}$ volume $(25 \%, 50 \%$, and $75 \%)$. $S_{R}$ decreases with increasing $d_{m}$, e.g. for $Q=20 \mathrm{l} / \mathrm{s}, S_{R}=0.20 \mathrm{~m}$ for $d_{m}=2.7 \mathrm{~mm}$ compared to $S_{R}=0.17 \mathrm{~m}$ for $d_{m}=5.4 \mathrm{~mm}$, and $S_{R}=0.03 \mathrm{~m}$ for $d_{m}=13.1 \mathrm{~mm}$. Scour due to LW accumulation can be described as a functional relationship with parameters increasing scour in the numerator and parameters decreasing scour in the denominator, i.e. $S \approx q / d_{m}$. As a next step, the results for $S$ will be compared with established formulas (e.g. [15, 19].

\section{Conclusions}

Hydraulic model tests were conducted to identify the effect of LW accumulations at retention racks on backwater rise and scour. The experiments were performed with a movable bed, including uniform and non-uniform material. The approach flow conditions, bed material, and initial conditions for sediment transport were varied. Backwater rise generally increases with increasing approach flow Froude number. The present study confirms the hypothesis that the resulting local scour due to LW accumulations reduces backwater rise. For the local scour, the unit discharge and the mean grain size diameter are the decisive parameters. Similar results for backwater rise and scour depth were obtained for both uniform and non-uniform 
bed material. Future research aims to enable the upscaling of the results for engineering application. It is the objective to combine the results of this study in a design equation for the expected backwater rise and scour depth.
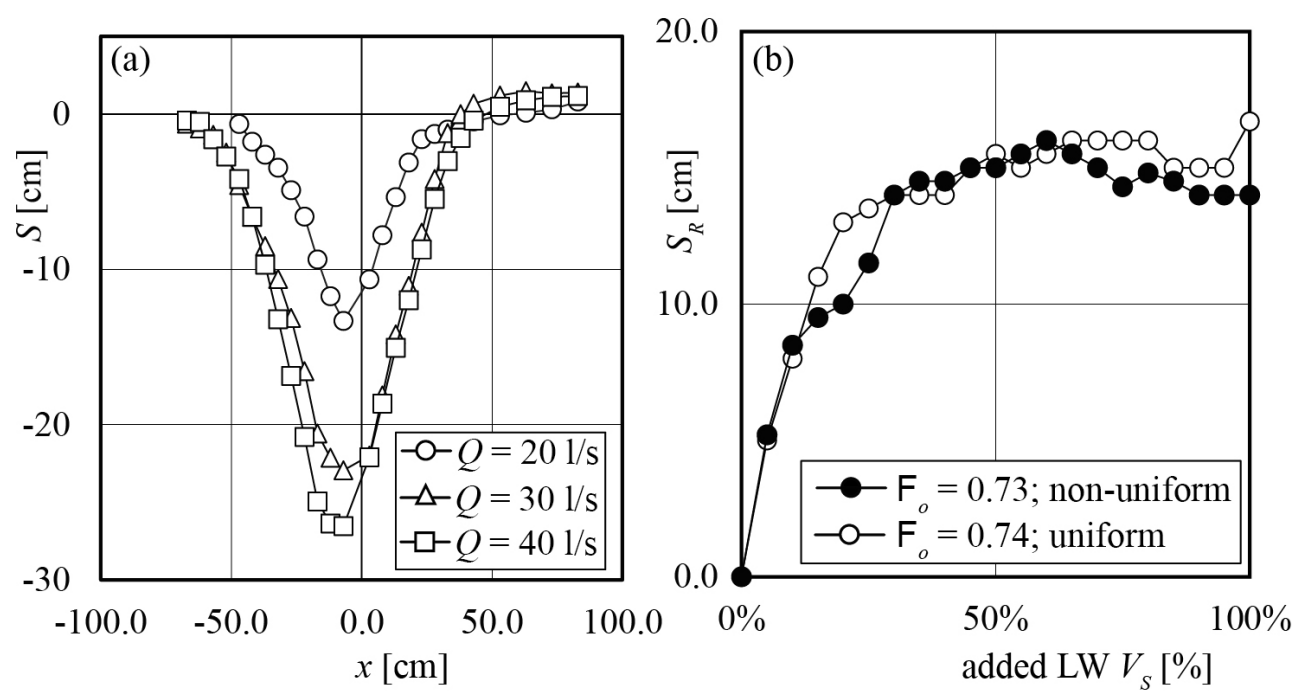

Figure 6. (a) Longitudinal-section of average cross-sectional scour depth $S$ for uniform bed material with $d_{m}=5.4 \mathrm{~mm}$ and various $Q$ (Tests A1-A7); (b) $S_{R}$ for increasing $\%$ of $V_{S}\left(\max . V_{S}=23 \mathrm{dm}^{3}\right.$ ) and uniform versus non-uniform bed material with $\mathrm{F}_{o} \approx 0.74$ and $d_{m} \approx 5.3 \mathrm{~mm}$ (Test A1 vs. A13)
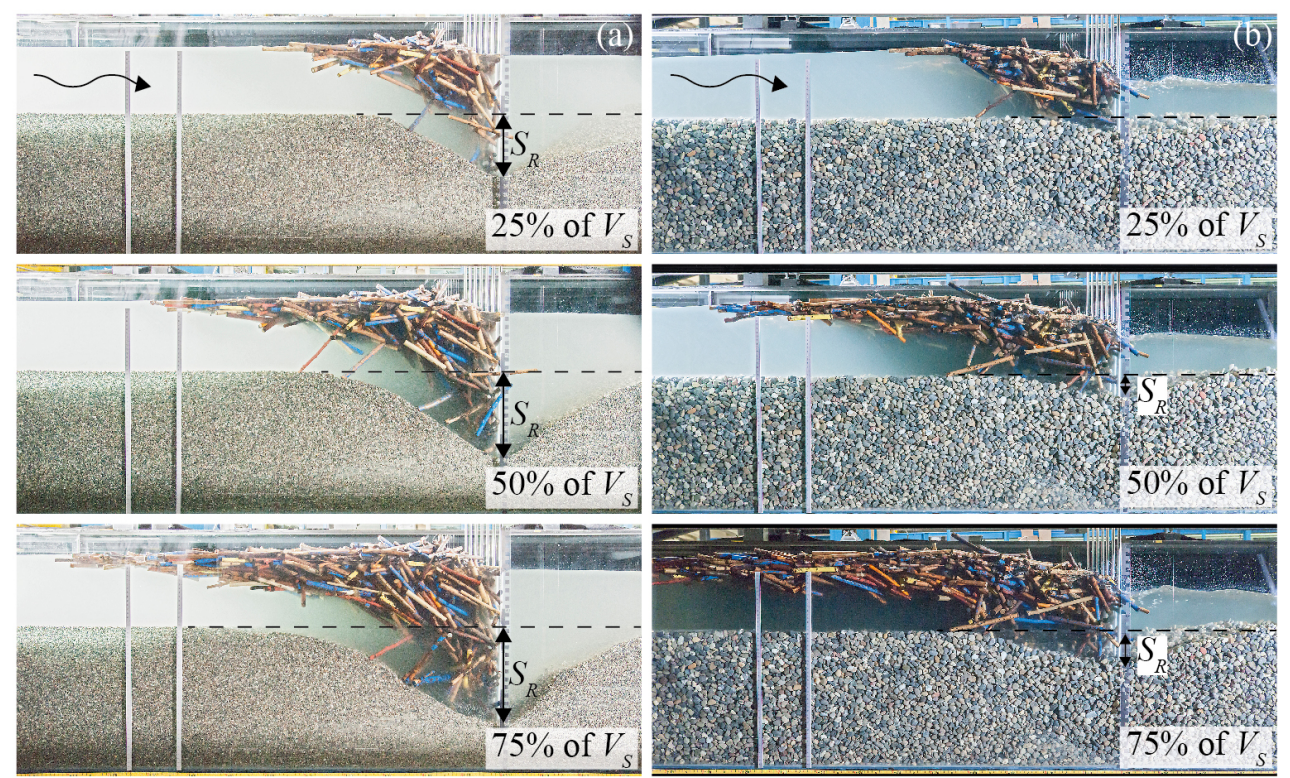

Figure 7. Scour development in hydraulic model tests with uniform bed material for $25 \%, 50 \%$, and $75 \%$ of $V_{S}, Q=30 \mathrm{l} / \mathrm{s}$ and (a) $d_{m}=2.7 \mathrm{~mm}$ (Test A9), (b) $d_{m}=13.1 \mathrm{~mm}$ (Test A12) 
The first author is financially supported by the Swiss Federal Office for the Environment, Grant 15.0018.PJ / O192-0202. The authors thank A. Höttges and C. Lageder for their laboratory assistance.

\section{References}

[1] E. Wohl, K. Jaeger, Earth Surf. Process. Landforms 34, 329 (2009)

[2] V. RuizVillanueva, H. Piégay, A.A. Gurnell, R.A. Marston, M. Stoffel, Rev. Geophys. 54, 611 (2016)

[3] E. Wohl, B.P. Bledsoe, K.D. Fausch, N. Kramer, K.R. Bestgen, M.N. Gooseff, JAWRA 52, 315 (2016)

[4] C.A. Braudrick, G.E. Grant, Y. Ishikawa, H. Ikeda, Earth Surf. Process. Landforms 22, 669 (1997)

[5] D. Ravazzolo, L. Mao, B. Mazzorana, V. Ruiz-Villanueva, Nat. Hazards Earth Syst. Sci. 17, 2053 (2017)

[6] J. Bradley, D. Richards, C. Bahner, Tech. Rep. FHWA-IF-04-016, U.S. Department of Transporation, Washington, DC, USA (2005)

[7] L. Schmocker, V. Weitbrecht, J. Hydraul. Eng. 139, 683 (2013)

[8] J. Knauss, Von der oberen zur unteren Isar ('From the upper to the lower Isar') (TU München, 1995), [in German]

[9] A. Rimböck, Schwemmholzrückhalt in Wildbächen: Grundlagen zu Planung und Berechnung von Seilnetzsperren ('Large wood retention in mountain torrents') (TU München, 2003), [in German]

[10] L. Schmocker, W.H. Hager, J. Hydraul. Eng. 139, 827 (2013)

[11] A. Hartlieb, Schwemmholz in Fließgewässern: Gefahren und Lösungsmöglichkeiten ('Large wood in rivers') (TU München, 2015), [in German]

[12] V. Ruiz-Villanueva, E. Bladé Castellet, A. Díez-Herrero, J.M. Bodoque, M. SánchezJuny, Earth Surf. Process. Landforms 39, 438 (2014)

[13] I. Schalko, L. Schmocker, V. Weitbrecht, R.M. Boes, in Proc. River Flow 2016 (CRC Press, 2016), pp. $2326-2332$

[14] E.M. Laursen, A. Toch, Scour around bridge piers and abutments, Vol. 4 (Iowa Institute of Hydraulic Research, 1956)

[15] B.W. Melville, D. Dongol, J. Hydraul. Eng. 118, 1306 (1992)

[16] P.F. Lagasse, L.W. Zevenbergen, P.E. Clopper, in Scour and Erosion (2010), pp. 854863

[17] S. Pagliara, I. Carnacina, J. Hydraul. Eng. 137, 254 (2010)

[18] N.P. Wallerstein, C.V. Alonso, S.J. Bennett, C.R. Thorne, Earth Surf. Process. Landforms 26, 1265 (2001)

[19] N.P. Wallerstein, Earth Surf. Process. Landforms 28, 49 (2003)

[20] V. Ruiz-Villanueva, A. Badoux, R.M. Boes, D. Rickenmann, C. Rickli, I. Schalko, L. Schmocker, M. Schwarz, N. Steeb, M. Stoffel et al., in Proc. River Flow 2016 (CRC Press, 2016), pp. $2307-2314$

[21] G. Bezzola, C. Hegg, Tech. Rep. 0707, FOEN, WSL (2007), [in German]

[22] I. Schalko, L. Schmocker, V. Weitbrecht, R.M. Boes, J. Hydraul. Eng. (2018), [in press]

[23] V. Ruiz-Villanueva, H. Piégay, V. Gaertner, F. Perret, M. Stoffel, CATENA 140, 182 (2016)

[24] E. Meyer-Peter, R. Müller, in Proc. 2nd IAHR congress, Vol. A2 (IAHR, 1948), pp. 1-26

[25] C. Lageder, Geschiebedurchgängigkeit von Schwemmholzrechen ('Sediment continuity at large wood retention racks') (Master Thesis, VAW, ETH Zurich, 2017), [in German] 